\title{
Research on The Ozone and Electromagnetic Cotreatment Technology of Papermaking Wastewater
}

\author{
Zhengshun Wang ${ }^{1,2,3}$, Mingchao $\mathrm{Chi}^{3}$, Kaitai Yao ${ }^{3}$, \\ Baiman $\mathrm{An}^{3}$, Zhihao Wang ${ }^{3}$ and Xianhao Wang ${ }^{3}$
}

\begin{abstract}
${ }^{1}$ State Key Laboratory of Biobased Materials and Green Papermaking Co-founded by Shandong and the Ministry of Science and Technology

${ }^{2}$ Key Laboratory of Pulp \& Paper Science and Technology of Education Ministry

${ }^{3}$ College of Paper and Plant Resources Engineering, Qilu University of Technology (Shandong Academy of Sciences),
\end{abstract}

3501 Daxue Rd, Changqing district, Jinan city, Shandong Province, P.R.China

Zhengshun Wang, wzsylq@aliyun.com

Keywords: papermaking wastewater, ozone, electromagnetic technology, cotreatment

Abstract. In this paper, ozone-electromagnetic technique was used to treat papermaking wastewater. It was found that the value of COD, BOD, TOC, SS, AN(Ammonia Nitrogen) and $\mathrm{CHR}$ (Chromaticity) of wastewater treated with the specially designed ozone sewage treatment unit decreased from $2660 \mathrm{mg} / \mathrm{L}, 1165 \mathrm{mg} / \mathrm{L}, 1962 \mathrm{mg} / \mathrm{L}, 707 \mathrm{~g} / \mathrm{L}, 112 \mathrm{mg} / \mathrm{L}$ and 120 times to $782 \mathrm{mg} / \mathrm{L}$, $118 \mathrm{mg} / \mathrm{L}, 684 \mathrm{mg} / \mathrm{L}, 112 \mathrm{~g} / \mathrm{L}, 16 \mathrm{mg} / \mathrm{L}$ and 50 times respectively. The values were reduced by $71 \%$, $90 \%, 65 \%, 84 \%, 86 \%$ and $58 \%$ respectively. The EC(Electrical Conductivity) increased by $2.1 \%$ slightly from $2800 \Omega^{-1} \cdot \mathrm{cm}^{-1}$ to $2860 \Omega^{-1} \cdot \mathrm{cm}^{-1}$. Subsequently, the treatment of papermaking wastewater was continued with graphite electromagnetic device.The results shown that the optimal treatment conditions were as follows: voltage $9.2 \mathrm{~V}$, current $1.72 \mathrm{~A}$, number of graphite plates in series 10, plate distance $3.24 \mathrm{~mm}$, treatment time $25 \mathrm{~min}$. Under these conditions, the value of COD, TOC, BOD, SS, AN, EC and CHR of papermaking wastewater can be reduced to $89 \mathrm{mg} / \mathrm{L}, 71 \mathrm{mg} / \mathrm{L}$, $53 \mathrm{mg} / \mathrm{L}, 33 \mathrm{~g} / \mathrm{L}, 8 \mathrm{mg} / \mathrm{L}, 68 \Omega^{-1} \cdot \mathrm{cm}^{-1}$ and 12 times, the removal rates are $97 \%, 94 \%, 97 \%, 95 \%$, 93\%, 98\%, 90\% respectively. By using the ozone system and electromagnetic equipment, the paper-making wastewater has achieved good results, which creates favorable conditions for wastewater reuse and zero discharge.

\section{Introduction}

Papermaking wastewater is a kind of high concentration wastewater with complex composition, which has a serious irritating smell. The main pollutants are inorganic pollutants (such as sulfides and inorganic salts), organic pollutants (such as ink, fine fibers and their degradation products, etc.) and microbes. The conventional treatment method of papermaking wastewater is biochemical process, which can basically achieve the standard discharge. However, with the severe shortage of fresh water resources, the cost of water is becoming higher and higher, even to the point where there is no water available in many arid areas. So the reuse of wastewater becomes more and more important. However, the reuse of papermaking wastewater brings many problems, one is that the odour of wastewater is difficult to remove, the other is that there are more and more anions and anions in the wastewater, and the electrical conductivity is higher and higher, which affects the normal papermaking operation. The 
purpose of this paper is to explore a method which is different from conventional sewage treatment to solve the problems of odour and high salinity caused by the reuse of papermaking wastewater.

Ozone is a strong oxidant with oxidation potential of $2.07 \mathrm{~V}$. Ozone has the characteristics of quick reaction with organic matter, no secondary pollution, local production, easy availability of raw materials and convenient use. Ozone can react with soluble and insoluble pollutants in water to convert complex organic matter into simple organic matter, and changes the polarity, biodegradability and toxicity of pollutants, and greatly reduces the value of the COD, BOD, TOC, SS , $\mathrm{AN}$ and CHR of the wastewater. The excess ozone can be decomposed into oxygen by itself. The ozone wastewater treatment is an effective and environmental-friendly method.

The basic principle of electrolysis and electromagnetism is used in the treatment of wastewater by electromagnetic technology. The harmful substances in the wastewater are enriched on the anode and cathode respectively, and they are oxidated and reduced, so that they can be converted into harmless substances or separated and concentrated to achieve the purification and separation of wastewater.

Graphite electrode has excellent electrical conductivity, high temperature resistance, chemical corrosion resistance, excellent chemical stability, not easy to reaction with other chemicals, so it has long service life, good economy, and is a good electromagnetic sewage treatment electrode selection.

The purpose of this paper is to make use of the advantage of strong oxidation of ozone to treat papermaking wastewater, and then to treat wastewater with advanced electromagnetic technology, and to further reduce the COD, BOD, TOC, SS , AN, EC and CHR of the wastewater, and to improve the water quality and achieve the purpose of wastewater reuse.

\section{Experiment}

Experimental Instruments and Chemicals. Electric drying oven with forced convection (DHG-9140A,Gongyi Yuhua Instruments co., Ltd.); BOD detector (LH-BOD601A, Lianhua Technology); Energy saving COD constant temperature heater (JHR-2, Shanghai Yetuo instrument Co., Ltd.); UV-Vis Spectrophotometer (Agilent, USA); TOC Analyzer (Dachang Huajia Commercial (China) Co., Ltd.); EC meter (Shanghai Thunder Magnetic DDSJ-308A type table conductivity meter);Ozone generator (Qingdao ODO environmental technology development Co., Ltd); Slag water separator (self-made); Papermaking wastewater (Huatai Paper Group sewage treatment plant); Potassium dichromate digestion solution(self-made); $\mathrm{H}_{2} \mathrm{SO}_{4}-\mathrm{Ag}_{2} \mathrm{SO}_{4}-\left(\mathrm{NH}_{4}\right)_{2} \mathrm{Fe}\left(\mathrm{SO}_{4}\right)_{2} \cdot 6 \mathrm{H}_{2} \mathrm{O}$ (Tianjin Damao Chemical Reagent Factory); Potassium sodium tartrate standard solution(self-made); Nessler's reagent (self-made).

The Detection Method of Main Index. Determination of ozone concentration: potassium iodide(KI)-sodium thiosulfate $\left(\mathrm{Na}_{2} \mathrm{~S}_{2} \mathrm{O}_{3}\right)$; Determination of biochemical oxygen demand $\left(\mathrm{BOD}_{5}\right)$; Determination of chemical oxygen demand (CODcr): Colorimetric method; Determination of ammonia nitrogen(AN): Nessler reagent photometry; SS determination: filtration drying weighing method. TOC determination: high temperature combustion catalytic oxidation method.

\section{Experimental Method .}

Ozone Treatment Method. The ozone concentration produced by the ozone generator is determined to be $28.6 \mathrm{ppm}$. The experimental process of ozone wastewater treatment is shown in 
fig.1. The papermaking wastewater was added to the storage tank as shown in fig.1, and then treated with ozone for 90 minutes.

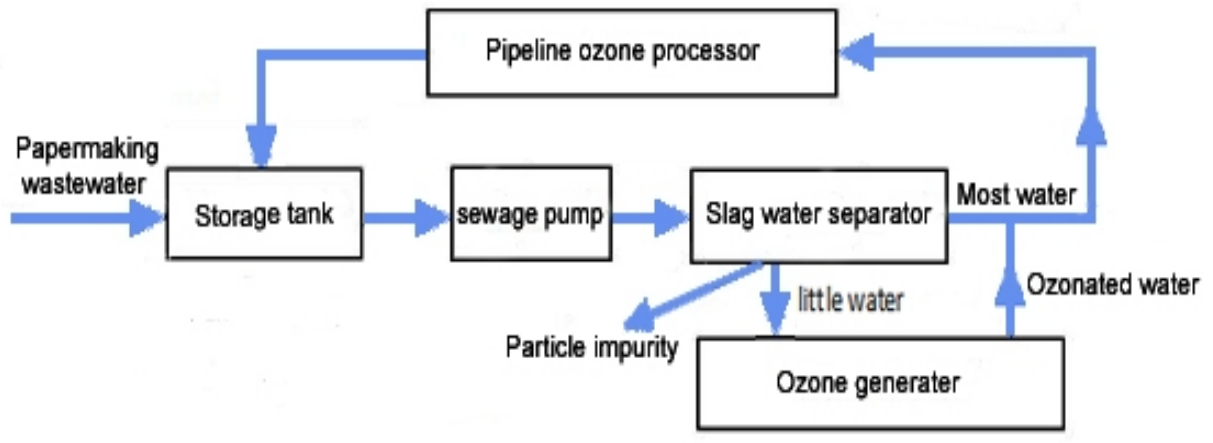

Fig.1 Experimental flow chart of ozone wastewater treatment

Electromagnetic Treatment Method.The graphite plate with microporous structure is used as electrode in this experiment, which provides a large specific surface area and a uniform flow channel, and provides a greater current density and better catalytic reaction effect for wastewater treatment. A special graphite electrode plate is used to recycle the wastewater sample. The experimental device is shown in fig.2. By changing the variables such as current and voltage, distance between electrode plates and reaction time, the effects of these factors on the treatment of wastewater by electromagnetic technology were researched, and the optimum technological conditions were obtained.

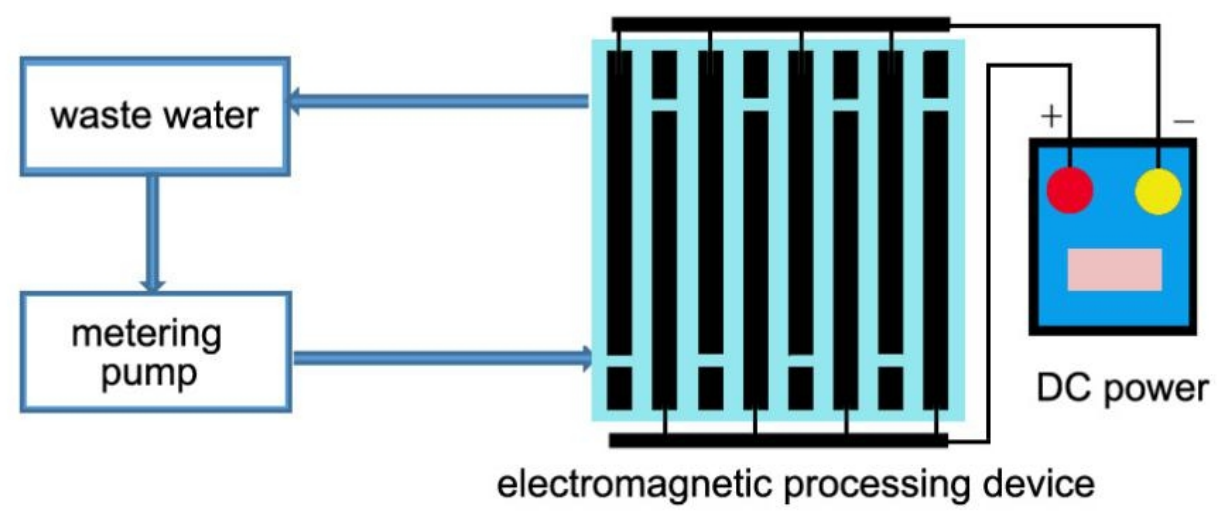

Fig.2 The diagram of the experimental equipment for electromagnetic processing

\section{Results and discussions}

Ozone Treatment Process. At $20^{\circ} \mathrm{C}, 220 \mathrm{~L}$ papermaking wastewater was added to the storage tank shown in figure 1. First open the sewage pump, then open the ozone generator. The curves of COD, BOD, TOC, SS, EC,AN and CHR as shown in Fig.3 are obtained by sampling every 10 minutes. 


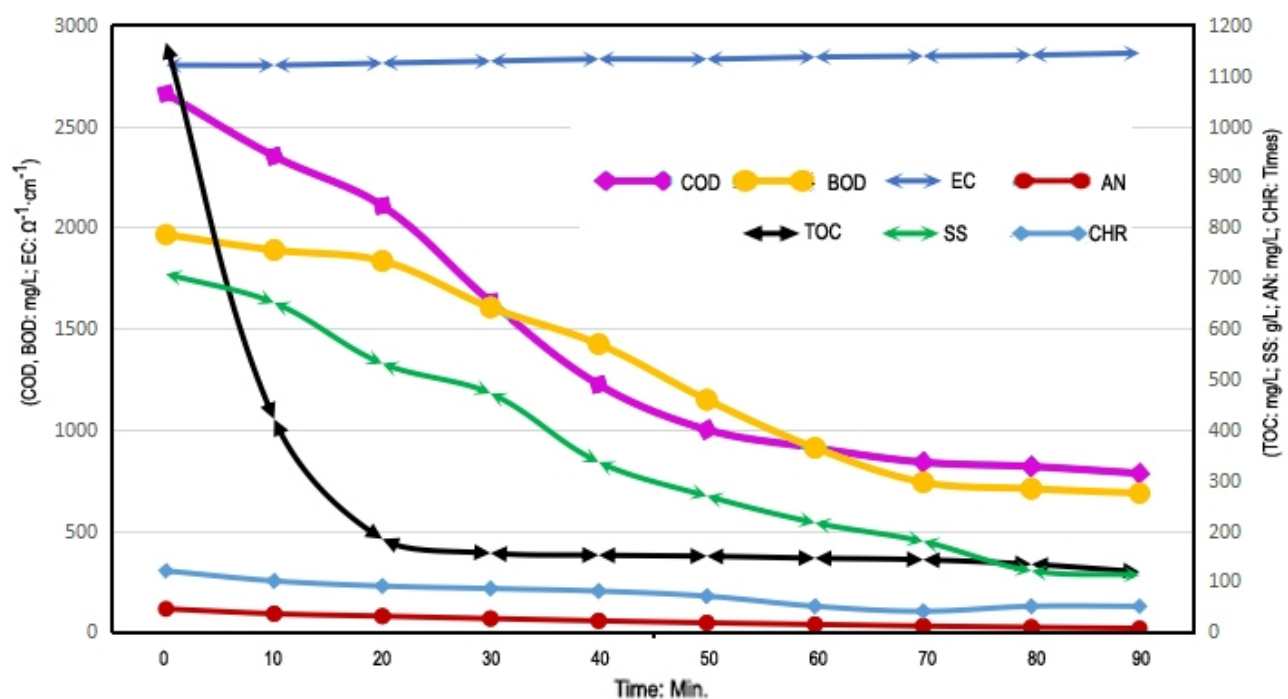

Fig.3 The curves of COD, BOD, EC, TOC, SS , AN and CHR with ozone treatment time

It can be seen from fig.3 that the value of COD, BOD, TOC, SS, AN, EC and CHR of papermaking wastewater decreases with the increase of ozone treatment time. After 90 minutes of ozonation treatment, it was reduced $71 \%, 90 \%, 65 \%, 84 \%, 86 \%$ and $58 \%$ from $2660 \mathrm{mg} / \mathrm{L}, 1165 \mathrm{mg} / \mathrm{L}$, $1962 \mathrm{mg} / \mathrm{L}, 707 \mathrm{mg} / \mathrm{L}, 112 \mathrm{mg} / \mathrm{L}$ and 120 times to $782 \mathrm{mg} / \mathrm{L}, 118 \mathrm{mg} / \mathrm{L}, 684 \mathrm{mg} / \mathrm{L}, 112 \mathrm{mg} / \mathrm{L}, 16 \mathrm{mg} / \mathrm{L}$ and 50times, respectively. It is obvious that ozone treatment is effective in reducing organic pollutants in sewage, especially for TOC, SS and AN. During the process, the conductivity increased by $2.1 \%$ from $2800 \Omega^{-1} \cdot \mathrm{cm}^{-1}$ to $2860 \Omega^{-1} \cdot \mathrm{cm}^{-1}$, which may be due to the formation of some organic acids during the oxidation and degradation of organic compounds by ozone. In economic terms, the best processing time is 70 minutes.

Electromagnetic Treatment Process. Further treatment of wastewater treated by ozone using electromagnetic device.

The Change of the Control Voltage with the Treatment Time. The control voltage is $5.1 \mathrm{v}$, the current is $0.74 \mathrm{~A}, 2$ pieces of graphite plate and the distance between the graphite plates is $1.08 \mathrm{~mm}$ (between the two plates is a layer of insulation net). The curve of the change of the control voltage with the treatment time is shown in Fig. 4.

As can be seen from Fig.4, in 0-30 minutes, the COD, TOC, BOD, SS, AN, EC and CHR of the wastewater have a tendency to decrease with the prolongation of the electromagnetic processing time. Before processing, the value of COD, TOC, BOD, SS, AN, EC and CHR was $782 \mathrm{mg} / \mathrm{L}, 118 \mathrm{mg} / \mathrm{L}$, $684 \mathrm{mg} / \mathrm{L}, 112 \mathrm{mg} / \mathrm{L}, 16 \mathrm{mg} / \mathrm{L}, 2860 \Omega^{-1} \cdot \mathrm{cm}^{-1}$ and 50 times respectively. And after 30 minutes of processing, it went down to $424 \mathrm{mg} / \mathrm{L}, 92 \mathrm{mg} / \mathrm{L}, 274 \mathrm{mg} / \mathrm{L}, 87 \mathrm{mg} / \mathrm{L}, 12 \mathrm{mg} / \mathrm{L}, 340 \Omega^{-1} \cdot \mathrm{cm}^{-1}, 30$ times, reduced by $46 \%, 22 \%, 60 \%, 22 \%, 25 \%, 88 \%, 40 \%$, respectively. It is obvious that after electromagnetic treatment, all the indexes of the wastewater are reduced to varying degrees, and the EC of the wastewater decreases to $88 \%$. Taken into account, the more suitable electromagnetic treatment time is 25 minutes. 


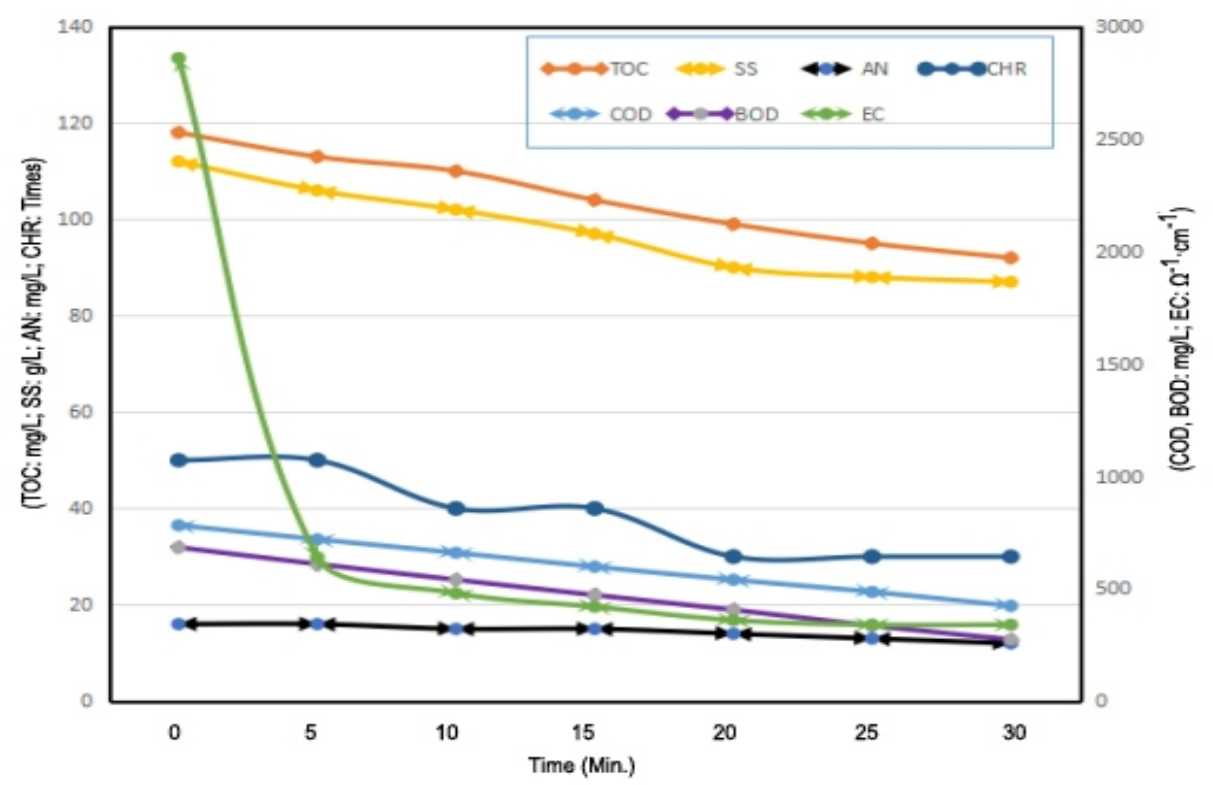

Fig.4 COD, BOD, EC, TOC, SS, AN and CHR curves with time

The Changes of COD, BOD, EC, TOC, SS, AN and CHR with Plate Distance. As can be seen from Fig.5, the distance between plates increases from $1.08 \mathrm{~mm}(1$ isolation net) to $5.40 \mathrm{~mm}(5$ isolation net). With the increase of plate distance, each index value of wastewater reaches the best value at $2.16 \mathrm{~mm}$ (2 isolation net). The values of COD, TOC, BOD, SS, EC, AN and CHR were $472 \mathrm{mg} / \mathrm{L}, 92 \mathrm{mg} / \mathrm{L}, 330 \mathrm{mg} / \mathrm{L}, 88 \mathrm{~g} / \mathrm{L}, 330 \Omega^{-1} \cdot \mathrm{cm}^{-1}, 13 \mathrm{~g} / \mathrm{L}, 30$ times respectively. Continue to increase the plate distance, the papermaking wastewater indicators will increase. Under this condition, the most suitable distance between electrode plates is $2.16 \mathrm{~mm}$ ( 2 isolation net) .

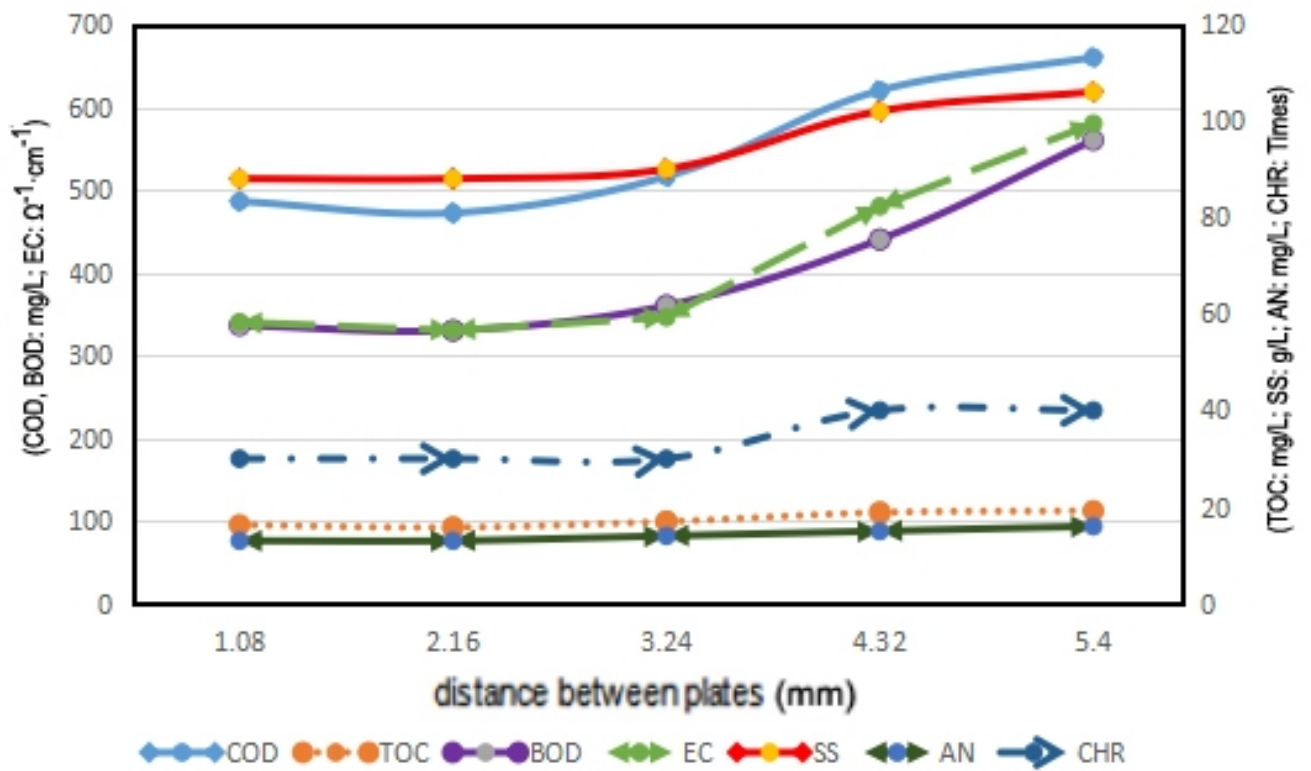

Fig.5 The curves of the changes of COD, BOD, EC, TOC, SS, AN and CHR with plate distance

The effect of the number of electrode plates on wastewater treatment. Control voltage $5.1 \mathrm{~V}$, current $0.74 \mathrm{~A}$, graphite plate distance $2.16 \mathrm{~mm}$, reaction time $25 \mathrm{~min}$. The effect of the number of 
electrode plates on wastewater treatment is studied, as shown in Table 1.

Table 1 The effect of the number of electrode plates on the papermaking wastewater treatment

\begin{tabular}{lcccccc}
\hline The number of electrode plates & 2 & 4 & 6 & 8 & 10 & 12 \\
\hline $\mathrm{COD}(\mathrm{mg} / \mathrm{L})$ & 470 & 375 & 260 & 180 & 120 & 122 \\
$\mathrm{TOC}(\mathrm{mg} / \mathrm{L})$ & 93 & 88 & 86 & 83 & 80 & 80 \\
$\mathrm{BOD}(\mathrm{mg} / \mathrm{L})$ & 320 & 220 & 140 & 80 & 60 & 65 \\
$\mathrm{SS}(\mathrm{g} / \mathrm{L})$ & 86 & 72 & 54 & 44 & 38 & 40 \\
$\mathrm{AN}(\mathrm{mg} / \mathrm{L})$ & 13 & 12 & 12 & 11 & 9 & 10 \\
$\mathrm{EC}\left(\Omega^{-1} \cdot \mathrm{cm}^{-1}\right)$ & 340 & 283 & 206 & 118 & 78 & 80 \\
$\mathrm{CHR}(\mathrm{times})$ & 30 & 28 & 25 & 20 & 15 & 20 \\
\hline
\end{tabular}

Can be seen from table 1, with the increase of the number of graphite electrode plates, the indicators of COD, TOC, BOD, SS, AN, EC and CHR of wastewater first decrease and then increase, the lowest point is at 10 electrode plates, and the values of COD, TOC, BOD, SS, AN, EC and CHR were $120 \mathrm{mg} / \mathrm{L}, 80 \mathrm{mg} / \mathrm{L}, 60 \mathrm{mg} / \mathrm{L}, 38 \mathrm{~g} / \mathrm{L}, 9 \mathrm{mg} / \mathrm{L}, 78 \Omega^{-1} \cdot \mathrm{cm}^{-1}$ and 15 times respectively. When the number increased to 10 , the removal effect is the most obviously best . Continue to increase the number of electrode plates, little change in the indicators. Therefore, the optimum number of electrode plates for electromagnetic treatment is determined to be 10 under this condition.

The Changes of COD, BOD, EC, TOC, SS, AN and CHR with Voltage and Current. Control the distance of graphite electrode plate to $2.16 \mathrm{~mm}$, the number of graphite plates 10 , the processing time $25 \mathrm{~min}$. By adjusting the voltage and current, the variation of each performance index is determined. The curves of the changes of COD, BOD, EC, TOC, SS, AN and CHR with voltage and current are shown in Fig.6. It is clear from Fig.6 that when the voltage varies from $5 \mathrm{~V}$ to $10 \mathrm{~V}$, with the increase of rated voltage and current, the value of COD, TOC, BOD, SS, AN, EC and CHR of the wastewater decrease from $130 \mathrm{mg} / \mathrm{L}, 80 \mathrm{mg} / \mathrm{L}, 60 \Omega^{-1} \cdot \mathrm{cm}^{-1}, 38 \mathrm{~g} / \mathrm{L}, 9 \mathrm{mg} / \mathrm{L}, 78 \Omega^{-1} \cdot \mathrm{cm}^{-1}, 15$ times to $90 \mathrm{mg} / \mathrm{L}, 70 \mathrm{mg} / \mathrm{L}, 55 \Omega^{-1} \cdot \mathrm{cm}^{-1}, 36 \mathrm{~g} / \mathrm{L}, 8 \mathrm{mg} / \mathrm{L}, 70 \Omega^{-1} \cdot \mathrm{cm}^{-1}$, 13 times, which decrease by $30.8 \%$, $12.5 \%, 8.3 \%, 5.3 \%, 11.1 \%, 10.3 \%$ and $13.3 \%$, respectively. When the voltage is between $10 \mathrm{v}$ and 30 $\mathrm{v}$, with the increase of rated voltage and current, the value of COD, TOC, BOD, SS, AN, EC and CHR of wastewater increases, and the voltage of $29.3 \mathrm{~V}$ is increased by $88.9 \%, 28.6 \%, 27.3 \%, 44.4 \%$, $12.5 \%, 34.3 \%$ and $38.5 \%$ respectively, compared with the voltage of $9.2 \mathrm{~V}$. This shows that the electrified voltage/current of papermaking wastewater treatment is the best choice at 9.2V/1.72A under the above conditions. 


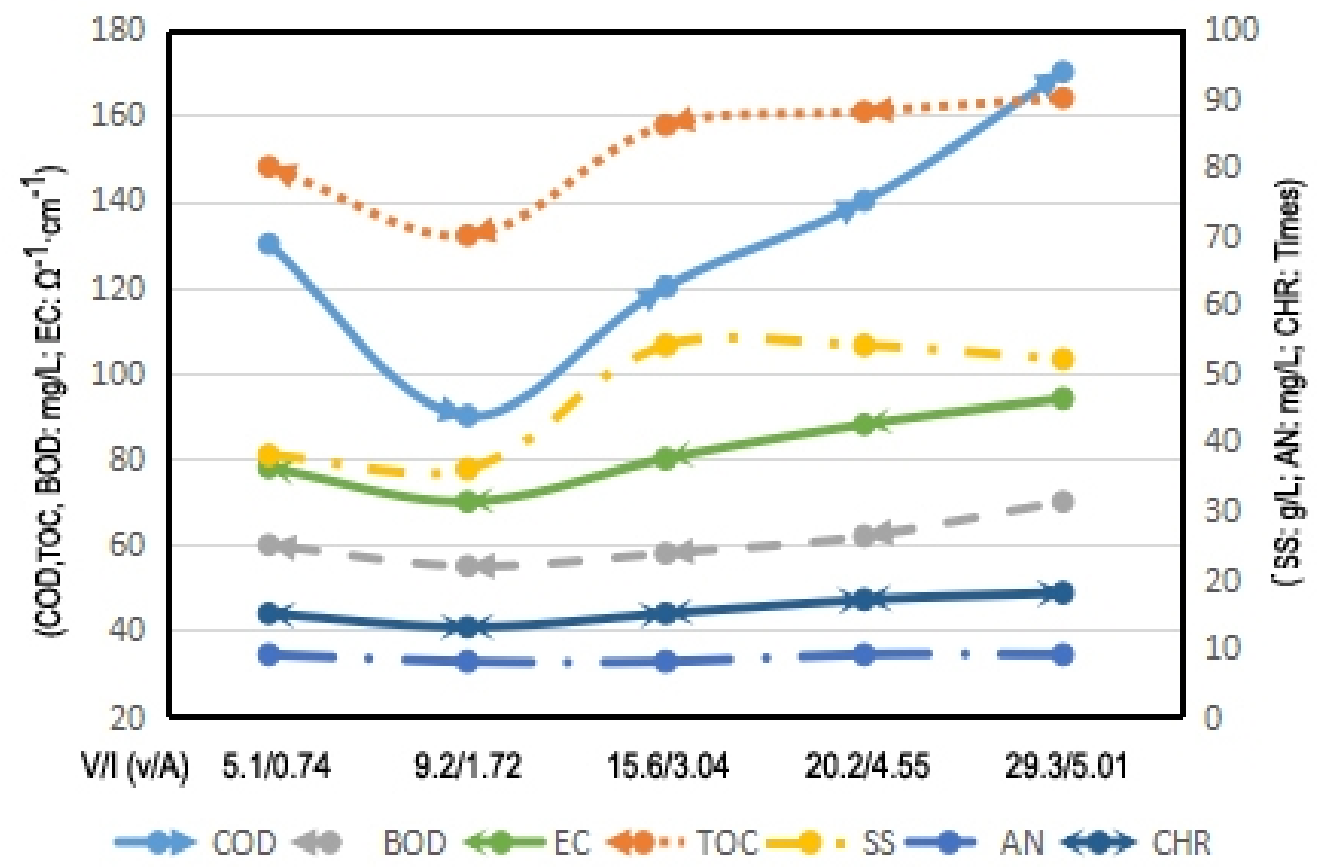

Fig.6 The effect of voltage/current on sewage treatment

\section{Ozonic-electromagnetic Treatment of Papermaking Wastewater under Optimal}

Conditions. Under the experimental conditions, the papermaking wastewater was treated with ozone generator for 70 minutes, then control the voltage at $9.2 \mathrm{~V}$, the current at $1.72 \mathrm{~A}$, the number of electrode plates is 10 , and the electromagnetic technique is used for 25 minutes. The experimental data of ozonic-electromagnetic treatment of papermaking wastewater is shown in table 2 .

Table 2. The experimental data of ozonic-electromagnetic treatment of papermaking wastewater

\begin{tabular}{lccccccc}
\hline & $\begin{array}{c}\text { COD } \\
(\mathrm{mg} / \mathrm{L})\end{array}$ & $\begin{array}{c}\text { TOC } \\
(\mathrm{mg} / \mathrm{L})\end{array}$ & $\begin{array}{c}\text { BOD } \\
(\mathrm{mg} / \mathrm{L})\end{array}$ & $\begin{array}{c}\mathrm{SS} \\
(\mathrm{g} / \mathrm{L})\end{array}$ & $\begin{array}{c}\mathrm{AN} \\
(\mathrm{mg} / \mathrm{L})\end{array}$ & $\begin{array}{c}\text { EC } \\
\Omega^{-1} \cdot \mathrm{cm}^{-1}\end{array}$ & $\begin{array}{c}\text { CHR } \\
\text { Times }\end{array}$ \\
\hline Before treatment & 2660 & 1165 & 1962 & 707 & 112 & 2800 & 120 \\
After ozone treatment & 782 & 118 & 684 & 112 & 16 & 2850 & 50 \\
$\begin{array}{l}\text { Reduced \% } \\
\text { After ozonic }\end{array}$ & 71 & 90 & 65 & 84 & 86 & -1.8 & 58 \\
-electromagnetic treatment & 89 & 71 & 53 & 33 & 8 & 68 & 12 \\
Reduced \% & 97 & 94 & 97 & 95 & 93 & 98 & 90 \\
\hline
\end{tabular}

As can be seen from table 2, the value of COD, TOC, BOD, SS, AN, EC and CHR of papermaking wastewater decreased to $89 \mathrm{mg} / \mathrm{L}, 71 \mathrm{mg} / \mathrm{L}, 53 \mathrm{mg} / \mathrm{L}, 33 \mathrm{~g} / \mathrm{L}, 8 \mathrm{mg} / \mathrm{L}, 68 \Omega^{-1} \cdot \mathrm{cm}^{-1}$ and 12 times from pretreatment $2660 \mathrm{mg} / \mathrm{L}, 1165 \mathrm{mg} / \mathrm{L}, 1962 \mathrm{mg} / \mathrm{L}, 707 \mathrm{~g} / \mathrm{L}, 112 \mathrm{mg} / \mathrm{L}, 2800 \Omega^{-1} \cdot \mathrm{cm}^{-1}$ and 120times, and the removal rates were $97 \%, 94 \%, 97 \%, 95 \%, 93 \%, 98 \%$ and $90 \%$ respectively, and the treatment effect is very good. It creates favorable conditions for waste water reuse and zero discharge. 


\section{Conclusions}

The composition of papermaking wastewater was complex and difficult to deal with them by the conventional biochemical technology. However, good results have been achieved by using ozone-electromagnetic technology.

Treatment of Papermaking Wastewater by Ozone Alone. Under the experimental conditions, the wastewater was treated with ozone alone for 90 minutes, the value of COD, BOD, TOC, SS , AN and CHR of wastewater decreased from $2660 \mathrm{mg} / \mathrm{L}, 1165 \mathrm{mg} / \mathrm{L}, 1962 \mathrm{mg} / \mathrm{L}, 707 \mathrm{~g} / \mathrm{L}, 112 \mathrm{mg} / \mathrm{L}$ and 120 times to $782 \mathrm{mg} / \mathrm{L}, 118 \mathrm{mg} / \mathrm{L}, 684 \mathrm{mg} / \mathrm{L}, 112 \mathrm{~g} / \mathrm{L}, 16 \mathrm{mg} / \mathrm{L}$ and 50 times respectively. The values were reduced by $71 \%, 90 \%, 65 \%, 84 \%, 86 \%$ and $58 \%$ respectively. The EC increased by $2.1 \%$ slightly from $2800 \Omega^{-1} \cdot \mathrm{cm}^{-1}$ to $2860 \Omega^{-1} \cdot \mathrm{cm}^{-1}$.

Papermaking Wastewater Cotreatment with Ozone and Electromagnetic Technology. The papermaking wastewater was treated with ozone generator for 70 minutes, then control the voltage at $9.2 \mathrm{~V}$, the current at $1.72 \mathrm{~A}$, the number of electrode plates is 10 , and the electromagnetic technique is used for 25 minutes. The value of COD, TOC, BOD, SS, AN, EC and CHR of papermaking wastewater can be reduced from $2660 \mathrm{mg} / \mathrm{L}, 1165 \mathrm{mg} / \mathrm{L}, 1962 \mathrm{mg} / \mathrm{L}, 707 \mathrm{~g} / \mathrm{L}, 112 \mathrm{mg} / \mathrm{L}, 2800 \Omega^{-1} \cdot \mathrm{cm}^{-1}$ and 120 times to $89 \mathrm{mg} / \mathrm{L}, 71 \mathrm{mg} / \mathrm{L}, 53 \mathrm{mg} / \mathrm{L}, 33 \mathrm{~g} / \mathrm{L}, 8 \mathrm{mg} / \mathrm{L}, 68 \Omega^{-1} \cdot \mathrm{cm}^{-1}$ and 12 times, the removal rates are $96.7 \%, 93.9 \%, 97.3 \%, 95.3 \%, 92.9 \%, 97.6 \%, 90 \%$ respectively, and the treatment effect is verygood. Ozone synergistic electromagnetic technology is used to treat papermaking wastewater, which creates favorable conditions for wastewater reuse and zero discharge.

\section{References}

[1] Zhengshun Wang, Yingjie Liu. Study on ozone/Fenton reagent co-processing of wheat straw pulp hypochlorite bleaching wastewater. ISMEMS2016, p322-327

[2] Q X Tan. Municipal landfill leachate treatment technology and method. Engineering Technology, 2016, 2, No. 15:25-32

[3] B Y Yang. Application of landfill leachate treatment technology. Resource Information and Engineering, 2016,12,31,No.6:56-62

[4] C W Zou, Meisheng Xu, Hong Huang. Treatment technology of landfill leachate. Environment and Development, 2016, 16, No.3:23-25

[5] Zhengshun Wang, Tongcai Yang. Study on ozone treatment technology of waste paper pulping wastewater. ISMEMS2016, p316-321

[6] H W Li. Study on the treatment of black liquor and middle stage water in papermaking wastewater. Harbin University of Technology.2005, p33 